De Jure: Jurnal Hukum dan Syari'ah

Vol. 10, No. 2, 2018, h. 81-88

ISSN (Print): 2085-1618, ISSN (Online): 2528-1658

DOI: http://dx.doi.org/10.18860/j-fsh.v10i2.6724

Available online at http://ejournal.uin-malang.ac.id/index.php/syariah

\title{
Tradisi Sorong Serah Aji Krama: Upaya Memperkuat Hubungan Keluarga Suku Sasak
}

\author{
Lalu Alfian Zakaria \\ Universitas Islam Negeri Maulana Malik Ibrahim Malang \\ zakarialfian@gmail.com
}

\begin{abstract}
Abstrak:
\end{abstract}
Indonesian people have a rich variety of cultures and traditions, especially those related to marriage. Sorong Serah Aji Krama is one of the marital customs in Central Lombok which is currently carried out by only aristocratic groups (nobles) to perpetuate social status based on descent. The purpose of this study is to explain the views of community leaders on Sorong Serah tradition in the perspective of 'urf. This article comes from empirical legal research with a qualitative approach. The primary source of this research is taken from the results of interviews with the existing community leaders including religious teachers, village leaders and doers of sorong serah tradition. The secondary data comes from journal articles and literatures related to sorong serah tradition. The results of this study indicate that the tradition of Sorong Serah Aji Krama marriage has become a custom in Puyung Village, Jonggat District, Central Lombok Regency, and the custom does not violate the rules of Islamic Shari'a.

Masyarakat Indonesia memiliki kekayaan budaya dan tradisi yang beragam khususnya yang berkaitan dengan perkawinan. Sorong Serah Aji Krama adalah salah satu adat penikahan yang ada di Lombok Tengah yang saat ini pelaksanaannya hanya dilakukan oleh golongan bangsawan (ningrat) untuk melanggengkan status sosial berdasarkan keturunan. Tujuan penelitian ini adalah menjelaskan tentang pandangan tokoh masyarakat terhadap tradisi sorong serah dalam perkawinan adat suku sasak perspektif 'urf. Artikel ini berasal dari penelitian hukum empiris dengan pendekatan kualitatif. Sumber primer penelitian ini diambil dari hasil wawancara dengan para tokoh masyarakat yang ada, diantaranya penulis mewancarai para ustadz, kepala pemerintahan desa, dan pelaku adat sorong serah. Sedangkan data sekunder berasal dari artikel jurnal serta literatur yang berkaitan dengan sorong serah. Hasil penelitian ini menunjukkan bahwa tradisi pernikahan Sorong Serah Aji Krama sudah menjadi adat di Desa Puyung Kecamatan Jonggat Kabupaten Lombok Tengah, dan adat tersebut tidak menyalahi aturan syari'at Islam.

Kata Kunci: sorong serah; pernikahan; suku sasak

\section{Pendahuluan}

Indonesia merupakan negara yang memiliki tingkat kemajemukan yang tinggi. Hal ini terbukti dengan adanya keanekaragaman suku, etnis, serta agama yang dianut 
penduduk Indonesia. Keanekaragaman tersebut menjadikan masyarakat Indonesia memiliki kultur yang berbeda-beda. ${ }^{1}$ Salah satunya adalah budaya dalam pelaksanaan perkawinan. Keberagaman budaya masyarakat Indonesia menjadikan pelaksanaan perkawinan memiliki keunikan masing-masing. ${ }^{2}$ Be Berbagai tradisi perkawinan ini telah dilaksanakan sebelum Islam datang di nusantara.berapa kajian menunjukkan bahwa masyarakat adat di Indonesia masih melestarikan berbagai tradisi nenek moyang secara turun-temurun. Ahmad Pattiroy dan Idrus Salam menyebutkan adanya tradisi doi' menre' dalam perkawinan adat suku Bugis. Dalam tradisi ini calon mempelai lakilaki diminta menyerahkan sejumlah uang yang digunakan dalam resepsi perkawinan. Besarnya doi' menre' bergantung pada status sosial calon mempelai perempuan. ${ }^{3}$ Taufiqurrahman melakukan kajian terhadap tradisi nembot penganu yang dilakukan oleh Suku Paser. Tradisi ini mewajibkan pihak laki-laki memberikan sejumlah benda dan uang tunai kepada pihak perempuan sesuai dengan yang telah disepakati oleh kedua belah pihak. ${ }^{4}$

Pada dasarnya, Islam memberikan ketentuan yang mudah dan sederhana dalam pelaksanaan perkawinan. Perkawinan dianggap sah jika telah memenuhi syarat dan rukun. ${ }^{5}$ Meskipun demikian, Islam memberikan ruang bagi budaya lokal dalam pelaksanaan perkawinan, sepanjang tidak bertentangan prinsip-prinsip agama. Berkaitan relasi ajaran agama dan budaya lokal, Ali Sodiqin membagi pola relasi tersebut menjadi tiga: Pertama, pola tahmil (adoptive-complement). Sikap ini ditunjukkan dengan adanya ayat-ayat yang menerima dan melanjutkan keberadaan tradisi serta menyempurnakan aturannya. Misalnya masalah perdagangan dan penghormatan bulan-bulan haram. Kedua, pola tahrim (detructive). Sikap ini ditunjukkan dengan melarang kebiasaankebiasaan masyarakat Arab yang disertai dengan ancaman bagi yang melakukannya. Pelarangan yang dilakukan secara bertahap dan manusiawi. Misalnya larangan berjudi, minum khamr, praktik riba, dan perbudakan. Ketiga, pola tagyir (adoptivereconstructive). Al-Qur'an menerima tradisi Arab namun melakukan rekonstruksi dengan melakukan memodifikasi. Secara simbolik, suatu tradisi tetap dipertahankan, tapi ketentuan-ketentuan diubah. Seperti pakaian dan aurat wanita, lembaga perkawinan, anak angkat, hukum waris, ibadah haji, dan qishash-diyat. ${ }^{6}$

Salah satu tradisi yang masih ada dan dipraktikkan masyarakat adalah sorong serah aji Krama. Tradisi ini merupakan salah satu rangkaian prosesi pernikahan adat Suku Sasak, termasuk di Desa Puyung Kecamatan Jonggat Kabupaten Lombok Tengah. Secara historis, tradisi ini diperuntukkan untuk kelompok bangsawan untuk mempertahankan status sosial mereka. Namun dalam perkembangannya, tradisi ini juga dipraktikkan oleh masyarakat biasa. Tradisi ini sering digunakan untuk menunjukkan

\footnotetext{
${ }^{1}$ Gina Lestari, "Bhinnekha Tunggal Ika: Khasanah Multikultural Indonesia Di Tengah Kehidupan Sara," Jurnal Ilmiah Pendidikan Pancasila Dan Kewarganegaraan 28, no. 1 (27 Juni 2016): 31, https://doi.org/10.17977/jppkn.v28i1.5437.

2 St Hajar Hajar, Nur Lidiawati, dan M. Dahlan M, "Prosesi pernikahan adat di kelurahan cikoro' kecamatan tompobulu kabupaten gowa," Jurnal Adabiyah 18, no. 1 (30 Juni 2018): 51, https://doi.org/10.24252/jad.v17i118i1a4.

3 Ahmad Pattiroy dan Idrus Salam, "Tradisi doi' menre' dalam pernikahan adat bugis di jambi," $A l$ Ahwal: Jurnal Hukum Keluarga Islam 1, no. 1 (2008): 101-3.

${ }^{4}$ Taufiqurrahman Taufiqurrahman, "Nembot Penganu Sebagai Kearifan Lokal Suku Paser Perspektif 'Urf," Journal de Jure 10, no. 1 (30 Juni 2018): 47, https://doi.org/10.18860/j-fsh.v10i1.6606.

5 Itsnaatul Lathifah, "Pencatatan perkawinan: melacak akar budaya hukum dan respon masyarakat Indonesia terhadap pencatatan perkawinan," Al-Mazahib 3, no. 1 (2015): 41.

${ }^{6}$ Ali Sodiqin, Antropologi al-qur'an; model dialektika wahyu dan budaya (Yogyakarta: Ar-Ruzz Media, 2008), 116-17.
} 
status sosial masyarakat. Bahkan seringkali dianggap sebagai upaya mencari gengsi semata. Artikel ini berargumen bahwa tradisi sorong serah aji Krama bertujuan mengetahui dengan siapa mereka menjalin hubungan pernikahan, mempertautkan dan menyambung kekeluargaan. Selain itu, tradisi ini merupakan sarana publikasi adanya perkawinan bagi masyarakat Suku Sasak. Berdasarkan persoalan di atas, artikel ini bertujuan mendeskripsikan proses pelaksanaan tradisi sorong serah aji Krama dalam perkawinan adat Suku Sasak dan menganalisisnya berdasarkan 'urf.

\section{Metode Penelitian}

Penelitian termasuk dalam penelitian hukum empiris, yaitu dengan cara mengamati kegiatan atau fakta-fakta yang dianggap relevan dengan penelitian ini, kemudian melakukan penelitian untuk dapat menjelaskan serta mengembangkan fakta sesuai dengan hukum yang berlaku. Hal ini dikarenakan bahwa penelitian ini lebih menekankan pada data di lapangan sebagai objek yang diteliti, yaitu terkait tentang pandangan tokoh masyarakat terhadap praktik tradisi sorong serah aji Krama dalam pernikahan adat Suku Sasak perspektif 'urf di Desa Puyung, Kecamatan Jonggat, Kabupaten Lombok Tengah Nusa Tenggara Barat. Pendekatan yang dilakukan dalam penelitian ini adalah pendekatan kualitatif. Sumber data terbagi atas tiga sumber data yakni, Pertama data Primer. Data Primer ini diperoleh dari hasil wawancara peneliti dengan tokoh masyarakat setempat. Para informan tersebut diantaranya, kepada desa setempat, serta kepala dusun, dan para perangkatnya. Kedua, data Sekunder. Data ini diperoleh berdasarkan literatur berupa buku-buku, hasil penelitian yang berwujud jurnal, artikel, serta literatur yang membahas mengenai sorong serah. Ketiga, Data Tersier adalah suatu penunjang, yang mencakup bahan-bahan yang memberikan suatu penjelasan terhadap sumber data primer dan sekunder yang meliputi: kamus, ensiklopedi, dan bahan yang lainnya.

\section{Hasil dan Pembahasan}

\section{Desa Puyung dan Tradisi Perkawinan Masyarakat Suku Sasak}

Desa Puyung merupakan salah satu desa yang berada di wilayah Kecamatan Jonggat Kabupaten Lombok tengah. Desa ini memiliki luas wilayah $6.30 \mathrm{KM}^{2}$ yang terdiri dari 16 Dusun. Desa Puyung berbatasan dengan Desa Bunkate dan Desa Gemel di sebelah Utara, Sebelah Timur berbatasan dengan Kelurahan Leneng dan Desa Wakul, di sebelah Selatan berbatasan dengan Desa Sukarara dan Desa Batujai, dan di sebelah barat berbatasan dengan Desa Nyerot. Kondisi geografis Desa Puyung adalah datar dengan tanah lempung yang sangat subur sehingga mayoritas penduduknya bermata pencaharian sebagai petani. Disamping pertanian masyarakat juga mengembangkan peternakan sapi yang terletak di Dusun Bunsumpak, Bangket Tengak, Dasan Ketujur, Otak Desa, Taman Daye, Kerembeng, Mosok, Lemerek.

Jumlah Penduduk Desa Puyung pada akhir tahun 2016 sejumlah 13.463 jiwa dengan rincian 6.408 jiwa berjenis kelamin laki-laki dan perempuan sebanyak 7.055 jiwa. Jumlah Keluarga di Desa Puyung sejumlah 4.545 Kepala Keluarga, dimana lakilaki yang menjadi kepala keluarga berjumlah 3.827 orang sedangkan perempuan yang menjadi kepala keluarga berjumlah 718 orang. Mengingat Desa Puyung merupakan Desa Agraris di mana hampir seluruh masyarakat Desa Puyung menaruh 
perekonomiannya pada sektor pertanian, perdangangan, industri rumah tangga dan jasajasa lainnya. Pertama, sektor pertanian. Sebagian besar masyarakat desa puyung masih mengandalkan Pertanian sebagai mata Pencariannya dimana tercatat ada 898 KK sebagai petani dan ada $670 \mathrm{KK}$ sebagai buruh tani dan tercatat ada 16 Kelompok Tani yang ada di Desa Puyung dengan luas wilayah pertanian di Desa Puyung mencakup 460 Ha lahan Pertanian.

Kedua, sektor Perternakan. Karena masyarakat kita masyarakat Petani maka para petani juga untuk meningkatkan perekonomiannya melalui berternak terutama berternak sapi, tercatat ada 16 Kelompok Tani ternak yang memelihara Sapi, dengan jumlah anggota 400 orang. Ketiga, sektor Perdagangan. Perdangan juga dapat memberikan kontribusi yang begitu besar dalam meningkatkan pertumbuhan ekonomi di Desa Puyung teratat ada beberapa potensi dan pelaku usaha yang ada di Desa Puyung adalah sebagai berikut sebagai berikut: 1) Pasar Tradisional 1 unit dengan jumlah pedagang bakulan dan klontong yang ada sebanyak $125 \mathrm{KK}$; 2) Kios/lapak berjumlah 80 unit yang tersebar di 16 Dusun, dapat menyerap tenaga kerja sejumlah 80 orang karena usaha ini masih bersipat milik pribadi dan kebayakan kios yang ada berada di masing masing rumah pemilk kios; 3) Rumah makan/warung berjumlah 27 buah, dimana puyung terkenal dengan nasi balapnya sehingga masyarakat banak yang membuka warung makan nasi balap karena sangat-sangat membantu perekonomian keluarga sehingga rumah makan tumbuh begitu pesat di masing - masing dusun di Desa Puyung, tenaga kerja yang diserap sebanyak 70 orang; 4) Mini market berjumlah 4 buah dengan penyerapan tenaga kerja sebanyak 25 orang.

Keempat, Industri Rumah Tangga yang dapat mendukung perekonomian di Desa Puyung adalah usaha kerajinan tahu tempe yang berada di Dusun Lingkung Daye dan Dusun Bunsumpak tercatat ada 150 KK sebagai pengerajin Tahu Tempe, dimana usaha rumah tangga tersebut dapat menyerap tenaga kerja/buruh harian lepas sebanyak 290 orang. Industri rumah tanga yang dapat meningkatkan perekonomian masyarakat adalah Tenun Soket yang berada di Dusun Dasan Ketujur dan Dusun Bun Bao tercatat ada $54 \mathrm{KK}$ yang masih aktif sebagai penenun songket secara turun menurun. Kelima, sektor Jasa. Ada beberapa jasa yang ikut menigkatkan perekonomian di Desa Puyung antara lain: bengkel mobil 1 unit, bengkel sepeda 1 unit, bengkel las 4 unit, Pande besi 4 unit, heler 6 unit, ojek, tukang dan salon kencantikan.

Tidak jauh berbeda dengan desa-desa lain di Lombok Tengah, masyrakat Desa Puyung masih memegang teguh tradisi yang diturunkan dari generasi sebelumnya. Termasuk di antaranya adalah tradisi sorong serah. Sorong serah berasal dari kata sorong yang berarti memberikan dan kata serah yang berarti menyerahkan. Sorong serah merupakan salah satu bagian penting dari rangkaian upacara perkawinan adat Suku Sasak. Menurut Ahmad Fauzan, sorong serah dapat diartikan sebagai serah terima pembayaran uang yang dilakukan pihak mempelai laki-laki kepada keluarga pihak mempelai perempuan dalam proses perkawinan. Adapun jumlah pembayaran telah ditentukan sebelumnya oleh masyarakat setempat. Tradisi sorong serah lazim dijumpai setelah terjadinya merariq, yaitu melarikan anak gadis untuk dinikahi karena 
takut lamaran ditolak atau karena perbedaan status sosial di masyarakat. Tradisi sorong serah telah dipraktikkan masyarakat Suku Sasak secara turun temurun. Tidak melaksanakan tradisi ini merupakan aib bagi keluarga dan masyarakat setempat. ${ }^{7}$

Tradisi sorong serah digunakan untuk menyerahkan aji Krama, yaitu pembayaran yang telah disepakati sebelum pelaksanaan perkawinan dan denda-denda adat. Penyerahan aji Krama merupakan simbolisasi status sosial kedua mempelai, terutama mempelai perempuan serta anak keturunan yang dilahirkannya. ${ }^{8}$ Mempelai perempuan yang berasal dari keluarga bangsawan maka nilai sorong serahnya lebih tinggi daripada mempelai perempuan yang berasal dari keluarga jajarkarang. ${ }^{9}$ Adapun aji krama untuk masing-masing calon mempelai perempuan sebagai berikut: Raden (100), Permenak (99), Perwangsa (66), dan jajar karang (33). Beberapa benda yang diserahkan dalam sorong serah memiliki makna yang luhur. Kain melambangkan kesiapan mempelai lakilaki memberikan kebutuhan sandang bagi istri dan anak-anaknya kelak. Keris melambangkan kesiapan mempelai laki-laki membela istri dan melindungi keluarganya. Sawah merupan simbol kesiapan laki-laki menuhi kebutuhan keluarga dan uang tunai merupakan simbil kesanggupan mencukupi kebutuhan rumah tangga. ${ }^{10}$

Upacara adat sorong serah lazim dilakukan dirumah calon mempelai perempuan. Calon mempelai laki-laki beserta rombongan yang terdiri dari dua puluh sampai tiga puluh orang untuk mendatangi keluarga pihak perempuan. Rombongan ini dengan membawa gegawan, yaitu barang-barang yang akan diserahkan kepada keluarga calon mempelai perempuan. Rombongan ini akan diterima oleh penanggap dari pihak keluarga calon mempelai perempuan. Rombongan ini bertugas menerima penyerahan aji Krama. Mengingat pentingnya acara ini, pihak calon mempelai laki-laki dan calon mempelai perempuan mengundang keluarga besar mereka untuk menjadi saksi dan menyambung tali kekeluargaan. Sorong serah dilakukan ketika prosesi nyongkalan dan dibarengi dengan upacara pembayunan.

Nyongkalan adalah prosesi perkawinan dimana untuk pertama kalinya kedua mempelai menunjukkan dirinya secara resmi di hadapan orangtua perempuan dan keluarga-keluarganya untuk memberikan penghormatan. Dalam tradisi ini perjalanan rombongan keluarga laki-laki menuju keluarga mempelai perempuan diiringi alunan alat-alat musik tradisional seperti rabana atau gendang belek. Dengan berakhirnya tradisi nyongkolan berakhirlah semua rangkaian upacara adat perkawinan Suku Sasak. Kedua mempelai pun telah resmi menjadi keluarga. ${ }^{11}$ Tradisi sorong serah dilaksanakan dalam sarana dialogis dan menekankan adanya musyawarah antara pihak mempelai laki-laki dan mempelai perempuan. Pihak laki-laki diwakili oleh beberapa orang untuk membawa aji krama dan dipimpin oleh seorang juru bicara yang disebut pembayun. Sedangkan perwakilan pihak mempelai perempuan diwakili oleh penemin. Dialog pada umumnya berisi tentang persoalan perkawinan kedua mempelai, diselingi pantun

\footnotetext{
${ }^{7}$ Ahmad Fauzan, "Sistem pertukaran orang sasak dalam prosesi sorong serah ajikrame," Sangkep: Jurnal Kajian Sosial Keagamaan 1, no. 1 (2018): 30-31.

${ }^{8}$ M. Najamudin Aminullah, "Kulturasi islam dengan tradisi perkawinan masyarakat bangsawan sasak (studi di kecamatan kopang kabupaten lombok tengah)," Palapa: Jurnal Studi Keislaman dan Ilmu Pendidikan 5, no. 1 (2017): 123.

${ }^{9}$ Fauzan, "Sistem pertukaran orang sasak," 37.

${ }^{10}$ Aminullah, "Kulturasi islam dengan tradisi perkawinan masyarakat bangsawan sasak," 122.

${ }^{11}$ Aminullah, 125-26.
} 
jenaka, dan berbagai nasihat kepada kedua mempelai tentang hak-hak dan kewajiban suami-istri dalam rumah tangga. ${ }^{12}$

Upacara sorong serah memiliki fungsi penting dalam kehidupan masyarakat Suku Sasak. Pertama, Tradisi ini merupakan sarana komunikasi dan publikasi perkawinan kedua mempelai kepada masyarakat. kepada masyarakat. Kedua, Tradisi ini juga memiliki fungsi mengembalikan keharmonisan hubungan masyarakat, khususnya keluarga mempelai pria dan mempelai wanita setelah terjadinya merariq. Acara ini untuk mendamaikan dua belah pihak keluarga yang mungkin berseteru setelah terjadinya merariq. ${ }^{13}$ Ketiga, Sorong serah juga berfungsi mempererat hubungan kekerabatan kedua belah pihak pasca perkawinan. ${ }^{14}$ Keempat, Sorong serah adalah suatu dorongan kepada kedua orangtua pengantin untuk menyerahkan atau melepaskan (serah terima) anak mereka untuk hidup berumah tangga. Kedua pengantin tidak lagi terikat pada kedua orangtua masing-masing. ${ }^{15}$

Tradisi sorong serah digunakan untuk menjaga stabilitas masyarakat Suku Sasak. Dalam tradisi sorong serah inilah berbagai konflik sosial yang bersumber dari perilaku kedua mempelai dan keluarganya diselesaikan. Tradisi ini juga memiliki makna penting dalam menjaga eksistensi hukum adat Suku Sasak, khususnya dalam prosesi perkawinan. Jika mempelai pria dan keluarganya terbukti tidak menjalankan proses perkawinan sesuai dengan ketentuan adat, maka mereka dikenai denda adat. Dalam konteks tertentu, tradisi ini juga dijadikan sebagai sarana menunjukkan status sosial seseorang di masyarakat. Keluarga mempelai perempuan yang tetap tidak setuju dengan perkawinan yang telah terjadi disebabkan perbedaan status sosial, maka pengantin perempuan akan dihapus dari daftar keluarga. ${ }^{16}$

\section{Tradisi Sorong Serah dalam Pernikahan Adat Sasak dalam Tinjauan 'Urf}

Akulturasi budaya merupakan bentuk interaksi Islam dengan tradisi lokal masyarakat Suku Sasak di pulau Lombok. Kebudayaan Suku Sasak yang bersumber dari keyakinan lokal tidak serta merta diubah begitu saja. budaya Sasak tidak digantikan dengan ajaran Islam secara keseluruhan, namun ajaran lokal Sasak itu dihiasi oleh ajaran fundamental yang terkandung dalam ajaran Islam. ${ }^{17}$ Kondisi ini juga diakui oleh Lalu Hendra Arya Purnama, salah seorang tokoh masyarakat Desa Puyung Kecamatan Jonggat Kabupaten Lombok Tengah. Beliau menyampaikan bahwa adat dan agama telah menyatu. Pelaksanaan tradisi sorong serah telah diwarnai dengan ajaran Islam. Misalnya melantukan asma-asma Allah SWT. Dalam upacara tersebut juga dibacakan doa kelesamatan untuk kedua mempelai. Adapun redaksi doa sebagai berikut: "kepada Allah SWT yang Maha Pengasih dan Maha Penyelamat dan kepada Nabi Muhammad Saw. pungkasan para nabi. Semoga kedua memepalai menjadi keluarga sakinah mawaddah wa rahmah". Hal ini menjadi bukti bahwa agama dan adat tidak bisa dipisahkan. Masyarakat Suku Sasak mengikuti ajaran-ajaran para ulama. ${ }^{18}$

\footnotetext{
12 Fauzan, "Sistem pertukaran orang sasak," 41.

${ }^{13}$ Mohamad Nur Yasin, Hukum perkawinan islam sasak (Malang: UIN-Malang Press, 2008), 226-28.

${ }^{14}$ Fauzan, "Sistem pertukaran orang sasak," 39.

15 M. Mahrif Zuhdi, Praktek Merarik: Wajah Sosial Masyarakat Sasak (Mataram: LEPPIM IAIN Mataram, 2012), 78.

16 Murdan, "Membaca perkawinan masyarakat islam sasak dari perspektif interlegalitas hukum," $A l$ Ahwal 10, no. 2 (2017): 119.

${ }_{17}$ Murdan, 120.

${ }^{18}$ Lalu Hendra Arya Puntara, Wawancara (Puyung: 19 April 2017)
} 
Lalu Harya Deni Prayata juga menyatakan bahwa sorong serah merupakan waris leluhur masyarakat Suku Sasak yang wajib dijaga dan dilaksanakan. Sorong serah memiliki tujuan yang baik. Seperti media pengumuman terjadinya perkawinan serta menjadi sarana menyambung dan memperkuat tali silatirahim di antara keluarga dan masyarakat. Selain itu, tradisi ini juga berfungsi membagi kebahagiaan dan rizki kepada orang lain dengan memberikan jamuan makan. ${ }^{19}$ Menurut Miftah Arifin, sorong serah merupakan media berkumpulnya dengan keluarga dan masyarakat untuk saling membantu dan tolong-menolong dalam pelaksanaan perkawinan. Hal ini selaras dengan ajaran Islam yang memerintahkan saling membantu, terlebih dengan sesama muslim. ${ }^{20}$

Tradisi sorong Serah tetap dipertahakan dan dilestarikan oleh masyarakat Suku Sasak yang menetap di desa Puyung Kecamatan Jonggat Kabupaten Lombok Tengah. Tradisi ini merupakan wadah bagi masyarakat untuk saling bahu-membahu, tolong menolong, dan berbagai dalam rangka merayakan atau mensyukuri atas pernikahan anak-anak mereka. Tradisi ini sekaligus sebagai pengumuman bahwa anaknya sudah menikah dengan wanita pilihannya. Agar tidak menjadi bahan fitnah ketika dilihat sedang berduan oleh masyarakat. Jika dilihat dalam konteks ini tradisi sorong serah termasuk dalam 'urf yang shahih. 'Urf yang shahih, yaitu satu adat atau kebiasaan yang berulang-ulang dilakukan, diterima oleh orang banyak, tidak bertentangan dengan agama, sopan santun, dan budaya yang luhur. ${ }^{21}$ Pelaksanaan sorong serah di Desa Puyung memegang teguh budaya yang luhur serta sopan santun. Berhubungan dengan penjelasan konsep 'urf diatas, maka disebutkan juga di dalam kaidah fiqh yang berbunyi العدةمحكمة yaitu suatu adat kebiasaan itu bisa dijadikan sebagai landasan hukum. Artinya suatu tradisi atau kebiasaan yang berlaku ditengahtengah lingkungan masyarakat yang tidak bertentangan, menyimpang, dan keluar baik dari al-Qur'an maupun dari hadist sehingga tidak menghilangkan kemaslahatan. Para ulama menetapkan beberapa syarat untuk menerima 'urf sebagai dasar hukum, antara lain: 1) Adat atau 'urf itu bernilai maslahat dan dapat diterima oleh akal sehat; 2) Adat atau 'urf itu berlaku umum dan merata di kalangan orang-orang yang berada di dalam lingkungan adat itu, atau kalangan sebagian besar warganya; 3) Urf yang dijadikan sandaran dalam penetapan hukum itu telah ada (berlaku) pada saat itu, bukan 'urf yang muncul kemudian; 4) Adat tidak bertentangan dan melainkan dalil syara' yang ada atau bertentangan dengan prinsip yang pasti. $^{22}$

\section{Kesimpulan}

Sorong serah aji krama merupakan tradisi pembayaran adat masyarakat Suku Sasak dalam perkawinan. Tradisi ini memiliki makna sosial yang penting, karena menjadi sarana publikasi terjadinya perkawinan, pembuktian status sosial bangsawan, mempererat tali kekeluargaan, dan membangun kembali keharmonisan dalam masyarakat. Pelaksanaan tradisi sorong serah aji krama di Desa Puyung Desa Puyung Kecamatan Jonggat Kabupaten Lombok Tengah termasuk dalam 'Urf yang sahih. Karena dilakukan secara berulang-ulang, sudah diterima oleh orang banyak, tidak bertentangan dengan agama, sopan santun, dan budaya yang luhur. Tradisi ini dapat dijadikan sebagai landasan hukum, artinya suatu tradisi atau kebiasaan yang berlaku

\footnotetext{
${ }^{19}$ Lalu Harya Deni Prayata, Wawancara (Puyung: 10 April 2017)

${ }^{20}$ Miftah Arifin, Wawancara (Puyung: 11 April 2017)

${ }^{21}$ Abdul Wahab Khallaf, Ilmu Ushul Fiqh, trans. oleh Faiz el Muttaqien (Jakarta: Pustaka Amani, 2003), 118.

${ }^{22}$ Amir Syarifuddin, Hukum islam di indonesia (Jakarta: Kencana, 2007), 400-401.
} 
ditengah-tengah lingkungan masyarakat yang tidak bertentangan, menyimpang, dan keluar baik dari Al-Qur'an maupun dari Hadist sehingga tidak menghilangkan kemaslahatan.

\section{Daftar Pustaka}

Aminullah, M. Najamudin. "Kulturasi islam dengan tradisi perkawinan masyarakat bangsawan sasak (studi di kecamatan kopang kabupaten lombok tengah)." Palapa: Jurnal Studi Keislaman dan Ilmu Pendidikan 5, no. 1 (2017).

Fauzan, Ahmad. "Sistem pertukaran orang sasak dalam prosesi sorong serah ajikrame." Sangkep: Jurnal Kajian Sosial Keagamaan 1, no. 1 (2018).

Hajar, St Hajar, Nur Lidiawati, dan M. Dahlan M. "Prosesi pernikahan adat di kelurahan cikoro' kecamatan tompobulu kabupaten gowa.” Jurnal Adabiyah 18, no. 1 (30 Juni 2018): 49-63. https://doi.org/10.24252/jad.v17i118i1a4.

Khallaf, Abdul Wahab. Ilmu Ushul Fiqh. Diterjemahkan oleh Faiz el Muttaqien. Jakarta: Pustaka Amani, 2003.

Lathifah, Itsnaatul. "Pencatatan perkawinan: melacak akar budaya hukum dan respon masyarakat Indonesia terhadap pencatatan perkawinan." Al-Mazahib 3, no. 1 (2015).

Lestari, Gina. "Bhinnekha Tunggal Ika: Khasanah Multikultural Indonesia Di Tengah Kehidupan Sara." Jurnal Ilmiah Pendidikan Pancasila Dan Kewarganegaraan 28, no. 1 (27 Juni 2016). https://doi.org/10.17977/jppkn.v28i1.5437.

M. Mahrif Zuhdi. Praktek Merarik: Wajah Sosial Masyarakat Sasak. Mataram: LEPPIM IAIN Mataram, 2012.

Murdan. "Membaca perkawinan masyarakat islam sasak dari perspektif interlegalitas hukum." Al Ahwal 10, no. 2 (2017).

Pattiroy, Ahmad, dan Idrus Salam. "Tradisi doi' menre' dalam pernikahan adat bugis di jambi." Al-Ahwal: Jurnal Hukum Keluarga Islam 1, no. 1 (2008): 89-116.

Sodiqin, Ali. Antropologi al-qur'an; model dialektika wahyu dan budaya. Yogyakarta: Ar-Ruzz Media, 2008.

Syarifuddin, Amir. Hukum islam di indonesia. Jakarta: Kencana, 2007.

Taufiqurrahman, Taufiqurrahman. "Nembot Penganu Sebagai Kearifan Lokal Suku Paser Perspektif 'Urf." Journal de Jure 10, no. 1 (30 Juni 2018): 40-48. https://doi.org/10.18860/j-fsh.v10i1.6606.

Yasin, Mohamad Nur. Hukum perkawinan islam sasak. Malang: UIN-Malang Press, 2008. 